[Cowie, B., Jones, A., \& Harlow, A. (2006). The Digital Horizons: Laptops for Teachers' Policy Initiative: Impacts and Consequences. New Zealand Annual Review of Education, 15, 111-131]

\section{The Digital Horizons: Laptops for Teachers' Policy Initiative: Impacts and Consequences}

\section{BRONWEN COWIE, Alister JONES AND ANN HARLOW}

\section{Abstract:}

This article draws from the findings of the secondary school Digital Horizons: Laptops for Teachers research study, to discuss the impact of a policy tool intended to assist teachers use information and communication technologies (ICT) for administration, communication, collaboration, lesson planning and preparation, as well as for classroom lessons themselves.

The results from a national questionnaire, focus group and case study evaluation indicate that secondary teachers are making more use of the laptops for communication with colleagues, reporting to parents, and the development of classroom materials than for use in the classroom for teaching and learning. Teacher commentary indicates that school technological infrastructure and access to professional development both constrain and enable their use of their laptops.

Drawing on Engelbart's notion of improvement infrastructure we discuss factors that have the potential to accelerate the integration of the laptop into teachers' professional lives. Analysis suggests that these factors include school and departmental leadership as well as the nature of the professional development that teachers experience. Engelbart (1992) argued that it was the factors at this level that were most important if the benefits of policy initiatives were to be maximized for teachers, schools and governments.

I.

ternationally, governments have endorsed the need for citizens to be ICT literate (OECD, 2001) and there has been significant investment in computers for schools in a number of countries including England, Singapore, Australia and New Zealand. Also evident in government policy internationally is the view that ICT can enhance, some would argue transform, teaching and student learning. More recently, governments in the United Kingdom, Australia and New Zealand, to name but a few, have moved to provide teachers with laptops. This paper discusses and illustrates the impacts and issues associated with New Zealand secondary teachers' access to laptops via the Digital Horizons: Laptops for Teachers scheme (TELA) (Ministry of Education, 2003). The orientation of this paper is to consider the impact of that policy initiative from both an "outside-in" and an "inside-out" perspective (Knapp, 2002).

The Digital Horizons: Learning through ICT (Ministry of Education, 2002 ) is the foundation policy document for ICT in the New Zealand compulsory education sector. It outlines the government's goals in relation to ICT as an area of knowledge relevant to all students. There is a commitment to increasing the use of ICT in schools, both to provide students with the skills and knowledge they need to achieve "personal goals" and become "full participants in the global community" (Ministry of Education, 2002, p. 3), and as a tool to enhance teaching practice and student achievement. From 2003, the TELA scheme (one component of this policy) has provided full-time teachers in secondary schools (Years 9 to 13) which opted in to the scheme with access to a laptop for minimal or no cost. The scheme has since been expanded to include Years 1 to 13 teachers, but the stated goals have remained the same - to develop teacher confidence and competence in the use of ICT for professional growth and collaboration, for teaching and learning, and for administration. Schools gain access to laptops for their teachers on the condition that the school manages the integration of the laptops into the school environment. This includes providing and meeting the costs of additional ICT infrastructure, professional development and technical support. The Ministry information package for the scheme states that a school's commitment to these requirements is "essential for an application to succeed" (Ministry of Education, 2003, p. 4)

The Digital Horizons: Laptops for Teachers evaluation was set up to evaluate the impact of the la ptops on teachers' work, specifically teacher professional growth and development, lesson planning, assessment and administration. Data have been generated through yearly cycles of questionnaires, focus groups and school case studies, starting from 2003.

In exploring teacher use of laptops we use Engelbart's notion of an improvement infrastructure and improvement community. Engelbart (1992) posits that organizations should aspire to creating three basic levels of infrastructure: a core capability infrastructure (this is what is 
needed to enable people to do the core work of the organization); an infrastructure that enables the improvement of core work, and an infrastructure that enables the on-going improvement of the improvement processes. Engelbart asserts that the third level is ultimately the most important to organizational effectiveness because it involves "getting better at getting better". He notes that the improvement-of-improvement level typically receives the least long-term strategic investment, but sustainability and maximising the impact of policy initiatives would seem to be vital in an environment where resources are limited. Applying Engelbart's framework to teachers with laptops, the third level of infrastructure is what enables teachers to improve their ability to enhance their use the laptop. In this paper we elaborate on New Zealand secondary teachers' uses of laptops to explain what afforded and constrained these uses, and outline those factors that have the potential to accelerate the integration of the laptops into teachers' professional lives.

\section{Establishing the First Level of Improvement Infrastructure:}

\section{The Teacher and the Laptop}

Government providing of laptops for teachers appears to be based on the assumption that access will foster teacher confidence and competence in the use of ICT and this will have flow-on effects for teaching and learning in schools. The literature provides very little support for this supposition in relation to computer use (Becker \& Ravitz, 1999; Cuban, 2001). When teachers use ICT/computers in the classroom they tend to use them to maintain their existing classroom practices (Harrison et al., 2003; Cuban, 2001). The TELA evaluation findings suggest New Zealand secondary teachers' use of their laptops in the classroom follows a similar pattern, although some participating teachers outlined how PowerPoint presentations that incorporated static and dynamic images and audio had enhanced, and in some instances transformed, their practice (Cowie, Jones \& Harlow, 2005). Congruous with research findings that innovation takes time, many of the evaluation study participants in 2004 and 2005 considered they were just beginning to realise the full range of potential benefits of laptop ownership. Learning more about how to use the laptop as a tool for teaching and supporting learning was the main goal for nearly a third of questionnaire respondents and most focus group and case study teachers. Hennessey, Ruthven and Brindley (2004) suggest that if ICT is viewed as a cultural tool then the gradual influences of its use on pedagogy will lead to the evolution of teacher practice, thinking and attitudes, roles and approaches over time.

Bebell, Russel and O'Dwyer (2004) argue for a wide conceptualization of teacher ICT use, one that encompasses the opportunities that arise from teacher use of technologies such as the worldwide web, email and the digital camera. This broad focus is consistent with TELA policy (Ministry of Education, 2003). Teachers make extensive use of ICTs for tasks that support teaching and learning and administration (Bebell, Russell \& O'Dwyer, 2004; Cowie, Jones and Harlow, 2004, 2005; Dale, Robertson \& Shortis, 2004). In New Zealand in 2005, most secondary teachers reported using their laptop "routinely" for administrative tasks such as writing reports for parents, and recording student grades and monitoring progress. Over three quarters of teachers said they had used their laptops "routinely" to prepare student handouts or worksheets. While such tasks are not directly related to instruction it could be argued (and the focus groups made this point) that they benefit teaching and learning through the streamlining of in-class administrative and management tasks, such as the recording of absences and marks, as well as the organization and presentation of teaching materials. While these uses are not transformative, teachers with all lesson materials well-organized had more time and energy for teaching and interaction with students. For instance, one focus group reported that because they were confident that their lesson materials were well-presented and on-hand, they were more able to focus attention on listening to, and questioning, students. Another teacher described her use of the laptop to record formative assessment information that formed a basis for discussion and planning with students.

\section{Distinctive Features of the Laptop}

While the patterns of use of school computers outlined above parallel those in existing research, laptops afford different opportunities for teacher use of ICT due to their portability, the opportunity for teacher exclusive use, and their generally higher specifications than existing school computers.

- Portability and exclusive use

Laptops go a long way towards meeting the assertion of Means et al. (2003) that "any given technology can support learning only to the degree that it is available for frequent, integral use within and outside 
school" (p. 165). The portability of laptops, coupled with exclusive use, afford ongoing teacher access to the same set of ICT tools and products throughout the school day, and at home. Many TELA teachers reported using their laptops as a portable office which was their sole/main repository for administration and management forms, curriculum documents and schemes of work, unit and lesson plans, and assessment tasks, including NCEA requirements, resources and student results.

Teachers are taking advantage of the flexibility the laptops offer in time and place of use and using them before and after school, at home, at the weekend, and even while they are on holiday, involved in theatre productions and at sports events (Cowie, Jones \& Harlow, 2005; Cunningham, Kerr, McEune, Smith \& Harris, 2003; Windschitl \& Sahl, 2002). The TELA teachers appreciated the flexibility of the laptop in allowing them to design lesson materials at school in collaboration with colleagues, and at home within a family setting. This was seen as socially beneficial in that it brought people together, both at home and school. Some teachers reported that they now spent more time at home on schoolwork but that this was acceptable to them because they were not "shut away" from their family. On the other hand, three focus groups expressed concerns about "work creep", and were apprehensive that working at home would become an expectation, rather than a choice.

- Versatility, flexibility and better access to multimedia resources

ICT and computer-mediated forms of multimedia communication are fast becoming the norm (Long, 2001). Teachers realize and recognize the benefits of coupling the visual (static and moving imagery, and colour) with the aural through the use of video, simulations and animations. The TELA focus group and case study teachers were convinced of the benefits of image-based materials, stating that they stimulated and sustained student interest and enhanced understanding. Laptops allow teachers to access the internet either from school or from home, to bookmark preferred sites for future use, and to adapt materials and store them for immediate use in class. However, teacher use of the internet for teaching and learning is not without its challenges. Teachers need the skills to locate and adapt available resources, many of which are not designed for education. The sharing of useful sites with colleagues is important in this process. The TELA teachers raised the issue of needing to develop pedagogical content knowledge around the tailoring and use of web-based resources (see also Loveless, Devoogd \& Bohlin, 2001) Teachers were positive about the benefits of greater access to multimedia resources such as educational and other websites, CD ROMs and digital cameras. Digital resources are easy to modify and can be readily shared. Laptops affording the production and sharing of digital resources fit well with the collaborative culture of many departments. Departmental mentoring and leadership, either from a head of department and or ICT expert within a department, were said to be vital to encourage the development and sharing of electronic lesson materials, and the setting up of a well-organized central repository for lesson materials.

- Increased connectivity and networking

The internet and email have become more dominant over the past ten years. Information on the internet is accessible in a networked way, and people can communicate and collaborate interactively via email and the internet. This networking of people and information can be local, regional or global. A stable and robust school intranet can enhance pooling and mutual sharing of resources to enhance teaching and learning, and lead to efficiencies in administration. Laptops afford teacher access to web-based resources, and their introduction to schools has leveraged the introduction and/or enhancement of school internet access and school intranet facilities. The TELA laptops, in conjunction with robust intra- and inter-net systems, have supported and enhanced communication and collaboration within and across departments and schools (Cowie, Jones \& Harlow, 2005). As might be expected, the use of email as a means for whole school communication, both formal and informal, was not seen as viable unless all staff possessed a laptop/computer, had easy access to the school network and could be relied on to use this facility on a regular basis. Teachers were now in more regular contact with a wider range of colleagues around the country to plan joint activities, including extra-curricula activities for students and meetings and conferences for teachers. Email has been used as a tool for sharing and collaboratively preparing lesson materials and, where teachers lacked home access to the school network, they emailed work to and from home and school. It seems likely that teacher use of email for professional and personal communication might provide an engaging entry point for teacher use of ICT, one that includes obvious and immediate feedback and efficiencies. 


\section{A diversity of teacher impacts and uses}

Policy is drafted on a national scale but it is variously interpreted before it impacts on individual teachers, who then make sense of it in ways that are shaped and framed by their own knowledge, skills and interests and the context in which they find themselves (Knapp, 2002; Spillane, 2004). Policy evaluation research that attends to individual teacher responses has highlighted the multiple demands on teachers' working lives and the diversity in the ways they make sense of and accommodate these demands (Knapp, 2002). As Windschitl \& Sahl (2002) point out, teacher response to ICT innovation is not necessarily predictable or even able to be generalized: teacher knowledge and expertise and beliefs about the potential of ICT to enhance teaching and learning influence their responses.

\section{Diversity arising from differences in teacher knowledge and expertise}

As might be expected, teachers' knowledge and expertise in the use of ICT is varied. Many of the teachers in the TELA evaluation study who intimated they were more skilled users indicated that while they appreciated having an up-to-date computer for their own use, access to a laptop had not substantially enhanced their knowledge and expertise, or their practice. There were exceptions to this, and some teachers were actively redesigning their teaching and learning programmes to incorporate multimodal, up-to-date and real-life materials. Those who rated themselves as less experienced users of computers reported substantial growth in their confidence, expertise and ICT use over the three years of data collection. Evidence of teacher learning came not so much from a higher proportion of teachers self-reporting as "expert" or "intermediate" users but from a shift in what those who rated themselves as "beginners" reported they could do with the laptop. Beginners were now more likely to be feel comfortable using their laptops for seven categories of use (word processing, using email, searching the internet, using graphics, using a spreadsheet, locating online information and using presentation software) and to use their laptops routinely for collaborative and administrative uses. "Beginners" were still not using their laptops routinely for lesson preparation activities. However, their "occasional use" of laptops for use as a tool for lesson preparation had almost doubled over the three years.
Diversity arising from the influence of teacher subject specialist area

Research on education policy, along with policy itself, tends to approach teaching as a generic practice. However Grossman, Stodolsky and Knapp (2004) make the point that "subject matter represents the crucible in which instructional reforms are enabled, as well as the direct target of many curricular reforms" (p. 3). They go on to assert that the impact of policy related to teaching is unlikely to be understood unless the interaction between policy and subject matter is examined. Recent research on teacher perspectives on the potential contribution of computers to teaching and learning supports the need to attend to subject matter as a player in teacher use of ICT (Hennessy, Ruthven and Brindley, 2004). Different subject subcultures, notably their pedagogical discourses and practices, shape teacher representation of ICT use, making visible, giving form, and according value to particular issues and approaches, although differences in individual teacher interpretations need to be kept in mind. English teachers in studies based in England and New Zealand, for example, placed more emphasis on student agency and face-to-face discussion as central to learning and were dubious of the role ICT could play in this. Mathematics teachers were somewhat ambivalent about the value of ICT/laptops - they used graphic calculators instead. In contrast, science teachers saw ICT as being able to contribute everyday examples and illustrations of ideas (Ruthven, Hennessey \& Brindley, 2004). In the TELA evaluation study a disproportionate number of science and technology teachers self-assessed themselves as expert users of the laptops. Science teachers from the case study schools were enthusiastic about the use of the laptop-plus-data projector/internet for teaching science. They reported extensive use of lesson materials that integrated text, simulations, interactives and real-world data (images and video clips) to stimulate student interest and engagement. Similarly, technology teachers were enthusiastic about the laptops as a tool to access/search the internet for information and for PowerPoint presentations, these often incorporating digital photographs of student work and Computer Aided Design (CAD) demonstrations. Digital photographs were useful as a record and a tool for assessment. Physical education teachers used the video capabilities of the laptops for analysis, teaching and assessment of student performance, both individual and team, curricular and extra-curricular (tennis, golf, netball). Social science teachers in one school considered their area of expertise "lends itself nicely" to the use of PowerPoint, virtual field trips and websites such as Google Earth and 
Geographic Information Systems (GIS). These differences suggest the need for policy initiatives and associated professional development to be sensitive to subject-specific needs.

Diversity arising from individual access to school systems and peripherals in the classroom

Teachers in interviews made a distinction between easy and ongoing access to a data projector. Teachers were not prepared to make a commitment to the use of electronic resources unless they had reliable, and preferably ongoing, access to a data projector. The time and effort required to access and set up a data projector often exceeded any benefits that teachers anticipated, particularly since they envisaged as ideal the flexible use of the laptop as a tool to respond to student ideas and questions. They recounted how colleagues with reliable access used the laptop-plus-data projector as a "natural thing". Schools were slowly acquiring data projectors, although not as rapidly as teachers would have liked.

In secondary schools there appeared to be some reluctance to use laptops for some administrative tasks, as teachers continued to use computers in classrooms and staff work areas that were already connected to school administration systems. Additional factors that might be expected to influence the use of laptops for administrative tasks were having the facility to input data onto the school administrative system and obtain access to the school network from within the school. Although the proportion of teachers with access from every classroom they taught in who used the laptop routinely for administrative tasks was different depending on the administrative task, it was evident that teachers with such access to the school network made more routine use of the laptop for administrative tasks than other teachers. Easy access to other equipment in the classroom made a difference to the use teachers made of their laptops during lessons. For example, those who had easy access to a data projector, scanner, printer, digital camera and/or video camera were more likely to use their laptops to produce lesson materials and to use the laptop as a teaching tool with students. Laptops have offered teachers a "portable office" but are more likely to be used routinely when there is reliable and convenient access both to school systems for administrative tasks in particular, and to peripherals for use in the classroom as a teaching tool. One respondent said: "We have trolleys in classrooms which have a computer, data projector and video player and a DVD player. So I am able to use my laptop for my work very effectively."

\section{Conceptualising the Second Level of Improvement Infrastructure}

Engelbart (1992) defines the second level of an improvement infrastructure as providing for improvement, in this case the improvement of teacher use of the laptops. Teacher commentary in the study indicated that professional development, school technological infrastructure, and school organisation and leadership shaped and constrained the opportunities and incentives teachers had to use their laptops. These factors influenced, in varying ways, all teacher uses of the laptops. But they manifested themselves in different ways for different teachers and for different uses of the laptop.

\section{Professional development}

Policy makers routinely use professional development as a tool to leverage change, and in the TELA scheme, schools and teachers were obliged to undertake 40 hours of professional development over the three years of the laptop lease. Despite this, the teachers were largely unaware of this requirement, and there was on-going uncertainty as to what could count towards the 40 hours. This said, just over a quarter of questionnaire respondents reported that they had received some professional development on school systems, beginning computer skills, some curriculum applications and the development of resources.

Teachers indicated that much of the available professional development was targeted to needs of beginning users. They argued that those with expertise needed opportunities to extend this. The main focus for professional development requested by teachers in 2005 was the development of skills that would help them to use their laptop as a teaching tool. Whole-staff professional development was recommended for institutionalised activities, such as reporting student absences and entering student assessment data, as a means of ensuring that consistency was maintained. It was also seen as having some value for skill development. Otherwise, generic professional development was said to lack immediacy and personal relevance.

As teachers sought to integrate the laptops into their work, supported by limited formal and funded professional development, they were turning to colleagues for help and support. Teachers identified peer mentoring and collegial support as the main mechanism for enhancing their use of the laptops for teaching and learning. In 2004 
and 2005 nearly three quarters had been helped by school ICT staff and a half by other teachers. Collegial help was described by those interviewed as the preferred and most prevalent form of professional development. Teachers acknowledged that certain individuals had particular expertise in ICT and emphasized the importance of opportunities to work in a sustained way with these colleagues as mentors. The professional development provided by same subject colleagues for ICT use in teaching and learning was seen to be especially valuable because it was "in context". Colleagues as mentors provided access to models of how a laptop could be used for teaching within the setting that teachers found themselves in. Some departmental leaders orchestrated the development and sharing of collective expertise by sending interested staff to external courses and providing opportunities for them to share what they had learned. Departmental cultures of sharing and learning had emerged, catalysed by, and revolving around, exploring the possibilities available through the laptops/ICT. In this way, it appears that informal peer mentoring has the potential to enhance teachers' sense of belonging to a professional learning community (Senge, 1994). The general consensus was that without the collaborative culture that exists amongst New Zealand teachers very little progress would have been made in the use of the laptops/ICT.

\section{ICT infrastructure and support}

The provision of infrastructure, particularly computers, has tended to be the focus of ICT policy initiatives with an associated focus on student-computer ratios as an indicator of the success of these policies (Dale, Robertson \& Shortis, 2004). Under the TELA scheme, schools are required to manage the integration of their laptops into the school environment, including the provision of additional ICT infrastructure and technical support (Ministry of Education, 2003). In this study, school technological infrastructure (including hardware, software and technical support), was described as a key constraint on teacher use of the laptops. The considerable variation in infrastructure provision and access amongst teachers within the same department and the same school, and between teachers in different schools was the key finding here.

There was some evidence of different histories and levels of initial familiarity with ICT in schools on entry to the TELA scheme, along with indication that this had consequences for the integration of the laptops into school and teacher practices. Teacher comments intimated that the nature of a school technological infrastructure was the culmination of various antecedent decisions by school leadership under the Tomorrow's Schools self-management regime (Lange, 1988). Schools where ICT had long been a strategic focus tended to have well-developed ICT systems and resources including hardware, software and personnel with the expertise required to provide advice and guidance in the development of school ICT policy and facilities. Staff from these schools indicated that in-school personnel had been able to anticipate some of the demands of the laptops and had planned to address these. At the other end of the continuum, schools that had joined the laptops scheme to "kick start" ICT developments in the school were working to connect all classrooms and to up-skill teachers. Teachers indicated that they were sharply aware of the variations in ICT development among schools and saw the TELA scheme as an opportunity to develop ICT within their school.

The introduction of laptops had prompted further investment in ICT infrastructure in almost all schools in the evaluation. The focus of this investment was qualitatively different in different schools, consequent on the existing technological infrastructure (hardware, software, and personnel with technical knowledge and expertise). It would seem that school technological infrastructure plays a crucial but different role at different times in teacher and school ICT development. Generally, professional development needs were seen as less pressing in schools with a poorly developed infrastructure. In these schools the teacher focus was on the need for school-wide networking. In schools with a more established infrastructure the laptops had prompted the purchase of additional ICT resources and, in some cases, ICT professional development. Increased teacher access to ICT/laptops and professional development led to increased demand for suites of computers for curriculum teaching and in-class data projectors.

\section{School leadership and support}

At this time a theme is emerging that senior management leadership is crucial irrespective of its form. In the initial stages, a leadership decision was required for a school to take part in the TELA scheme. Under the TELA scheme, teachers or their schools pay a portion of the lease for the laptops. The decision about who financed it was one that was made by the Board of Trustees with the principal. Some teachers reported their Board of Trustees saw the laptop as a personal item and were not prepared to fund the lease. Others explained that their Board and principal were actively pursuing a vision for ICT integration and were 
fully behind the scheme, to the extent of paying the lease costs. Teachers reported that the need to pay the lease cost had impacted on teacher participation in the scheme. Teachers were aware of the financial implications, and appreciated their Board's paying some, or all, of the lease. They saw the need to pay as an equity issue for teachers and students. Teachers considered they should not have to pay for a tool that was increasingly being positioned as central to their work.

Subsequent to a school entering the scheme, school policies and practices determined the incentives and opportunities teachers had to use the laptops. School polices about acceptable use reflected a meld of the TELA scheme requirements and the benefits and opportunities the school envisioned for teacher access to a laptop for their exclusive use. Some schools restricted teacher acceptable use of the laptops to school-related tasks; others allowed laptop use for all but inappropriate and objectionable tasks. Schools with a more flexible approach considered all teacher use could contribute to professional ends. In these schools the leadership focus was on reducing barriers, leading to wider use of the laptop, particularly by those with little confidence or expertise.

School leadership to develop policy and practice was exercised by different individuals in different schools. These individuals included the principal and/or member of the senior management (deputy principal), or a small group whose membership consisted of senior management, teachers with expertise in ICT, and/or enthusiastic individuals.

Focus group and case study teachers noted that, where the integration of ICT was part of the school strategic plan and supported by senior management and/or the Board of Trustees, the introduction of the laptops had been accompanied by careful planning for their integration into school systems. Teachers were very appreciative of this, and for the implicit valuing and support of their efforts in using the laptops. In some schools a lack of ongoing leadership to bring about successful ongoing support for laptop use had led to integration problems. For instance, in one school the consequence of low-level initial Board of Trustees and principal leadership support for ICT/laptops, had contributed to a very small teacher uptake of laptops. Continuing low-level support for actual use was considered by those interviewed to have contributed to a subsequent decline in the number of teachers with laptops. Where schools did not have active senior-level leadership for ICT the resulting vacuum was filled, or not, at the departmental level by the head of department and/or teachers with enthusiasm for and expertise in ICT. In these schools, ICT/laptop use was inconsistent and support for use was generally thought to be poor/inadequate by those interviewed. In sum, it would seem that leadership is important for initiating and sustaining the conditions that support teacher utilisation of laptops, and for helping teachers extend their use of the laptops. Without a clear vision and leadership at senior management level, school-wide development may be haphazard and ad hoc, dependent upon individual capability and interest.

Towards the Third Level of Improvement Infrastructure for Laptop Use Engelbart's (1992) third level of improvement infrastructure enables the on-going improvement of improvement processes. In other words, it is what accelerates teachers' ability to enhance their use of the laptop. A synthesis of the data across the three years (2003-2005) indicates that it is not sufficient to consider in isolation such matters as professional development, available ICT infrastructure, resources and support, and teacher confidence and expertise. It is the convergence of teacher confidence and expertise, the professional development they receive, as well as access to reliable ICT resources that supports the integration of the laptops into teachers' professional lives. It is these factors in combination that support and sustain, and/or inhibit teacher use of ICT/laptops. Individually and in combination, they are manifest as enablers and constraints in different ways in different school and departmental settings, and in different forms at different stages in the integration process.

For beginners, help to use the laptop, including prompt technical support, is important when they are "stuck". With more experienced and knowledgeable users, attention may turn to the development of lesson materials, the knowledge of resources to support this and the skills to make use of these resources. Once teachers are able to prepare multi-sensory materials, it seems that the focus shifts to the need for ongoing access to a data projector and models of how to use ICT for teaching and learning. Competent teachers who had classroom access to a data projector and the internet were eager for professional development to extend their knowledge and skills. They were interested in opportunities (and training on how) to share their enthusiasm and expertise with colleagues. As Salomon (1993) points out, the effectiveness of a tool, in this case the laptop, "results from and contributes to the whole configuration of events, activities, contents, and interpersonal processes taking place in the context of which it is being 
used" (p. 189). Clauses in the TELA scheme specifying that schools provide for school-based integration of the laptops with regard to professional development, technical support and technical infrastructure suggest that policy makers were aware of these dimensions. However, it seems probable that neither they, nor the schools, appreciated the full import of this requirement, or the way it was entangled with school interpretation and enactment of previous national policy, which had provided very little direction and support for ICT use. The findings highlight that school and teacher response to a particular policy do not take place in a vacuum. Responses are shaped by previous policies as they have become embedded in local organizational policies and practices and supporting material resources and technological infrastructures.

\section{Leadership shapes policy into practice}

The findings to date indicate that school leadership is crucial in providing the impetus, encouragement, and conditions for enhanced teacher professional use of laptops. It is a key component of the third level of a school improvement infrastructure. Like others (Anderson \& Dexter, 2000; Hayes, 2003), we found that school leadership, vision and support for teacher use of ICT/laptops, including the provision of ICT infrastructure and technical support, influenced the practical uses teachers made of a laptop. This interacted with the school and departmental culture for collaboration. School leaders, particularly the principal, were key in guiding the translation of the TELA policy into school-based policies and practices. As Hayes (2003) notes, principals need a vision for how technology might fit with and support student learning, they need to appreciate that the task of integrating ICT into schools is complex and risky. They have to manage the development of a stable and reliable technological infrastructure with the financial, knowledge and management risks to their own and the school's reputation that might arise from trying unproven methods. The challenge for school leaders is to establish and maintain a stable and accessible technological infrastructure and at the same time build teacher capability to use technology and integrate it into meaningful and well-designed learning programmes.

\section{The need for a critical mass of expertise and active use}

A critical mass of expertise and active laptop users is crucial to support and then extend individual teacher, department and whole-school laptop use. Where teachers within a school or department did not have a laptop, or a computer, this limited their involvement in some administrative and management tasks and the development and sharing of electronic lesson materials. Teacher commentary suggested that the more teachers within a department with laptops the more likely departmental colleagues were to collaborate using a laptop. That is, there needed to be a critical mass of teachers with laptops and those who used their laptops to establish and maximize the benefits of collaborative development and sharing of electronic resources. For example, teachers from three case study schools commented that the TELA restriction on part-time teachers accessing laptops restricted the use of the laptops for communication and collaboration within some departments. In contrast, all the teachers in the art department in one case study school had laptops. These teachers reported that the synergy between them contributed to the development of ICT use. A department workspace that was set up allowing collaboration and easy access to the internet and the school computer server was an important catalyst for departmental sharing. Three teachers from one technology department outlined the benefits they had accrued since the beginning of 2005 when their workroom had been cabled. Now, they could work together more efficiently, sharing and developing lesson materials. One of the teachers had accessed a laptop through the scheme so that he would not miss out on the gains being made.

\section{Professional development and the opportunity to share expertise}

In terms of the third level of improvement infrastructure, the findings of this study also attest to the importance of professional development: change would, in the teachers' opinion, have been greater with more professional support. Our findings resemble those of other researchers in New Zealand in according maximal value to peer mentoring and collegial help as a source of professional development (McGee et al., 2002; see also Garet, Porter, Desimone, Birman \& Yoon, 2001). However, if teachers and schools rely solely on collegial help and local good practice opportunities to learn, these are necessarily distributed in random and ad hoc ways (Dale, Robertson \& Shortis, 2004). Teacher access to someone with relevant expertise, and a willingness and ability to share, can influence opportunities to learn. That all teachers will have this access cannot be assured without some form of intervention. Added to this, teacher learning may be confined to what is available locally rather than what might be needed. What is needed is a balance between 
opportunities to share and to grow local knowledge and expertise. School-wide and departmental leaders in ICT, particularly those from smaller schools, need opportunities to meet with peers and experts from outside their own school to share problems and solutions. Once back at school, there needs to be a mechanism for these teachers to share with colleagues what they have learned, and for their colleagues to have time to experiment with and explore what has been learned. Principals, Boards of Trustees and school senior management need opportunities to extend their understanding of the potential and possibilities for ICT in their particular school. As Dale et al. (2004) point out, school-based policy and subsequent practices are often shaped by the principals'senior management's knowledge and expertise and the advice available to them. In the absence of sufficient experience and understanding of the issues to formulate questions, the tendency is to demand answers to locally shaped problems, and questions about possibilities are shaped by the available answers. The benefit of opportunities to share problems and solutions was amply demonstrated within the focus groups. When teachers sought advice on how to solve a particular problem, they were often surprised to find other schools managed the task in completely different ways. Given the evolutionary nature of ICT and its possible uses it seems likely that opportunities to share will continue to be important.

\section{Discussion}

All institutions face challenges with the integration of ICT (Langer, 2005). For schools these challenges have been exacerbated by the tendency for policy initiatives to be hardware-driven without a complementary investment in time and resources to develop teaching and learning. Computers have been provided to schools with very little consideration of teacher perspectives and the realities of classrooms (Selwyn, 1999). The findings of this evaluation study lend support to the contention that any analysis of the impact of ICT cannot afford to decontextualise it from the wider social and political variables that shape the larger context of schools (Selwyn, 2000); a systems analysis is required (Langer, 2005; Selwyn, 1999). As Olson (2000) suggests, policy makers need to "engage in conversations with teachers about their work culture, the technologies that sustain it and the implications of new approaches for those technologies" (p. 6).

Teacher commentary in this study attests to the efficacy of professional development as a policy tool, albeit not formal professional development provided by external experts. Indeed, data from this study suggest that the provision of externally developed and delivered courses needs careful consideration. Professional development deployed as a policy tool to build teacher capacity and inclination to use ICT/laptops may be better to focus on support for peer mentoring, and providing an allowance of teacher relief time in which teachers can practice new skills learnt. Easy access to models for teaching students using ICT would seem to be essential. This situation also has the additional benefit of supporting the development of schools as learning communities (Senge, 1994). Learning about the potential of ICT should not be limited to teachers. School leaders, including principals, senior management and Boards of Trustees, need opportunities to share and develop knowledge about how ICT and school strategic goals can be linked and reinforce each other.

Differences in school technological infrastructure indicate that government policies are not self-sufficient entities. School and teacher responses to a particular policy are shaped in part by antecedent policies and the ways in which these have played out in the local context. School ICT infrastructures also reflect this interaction. Schools with better-established ICT policies and practices not only had more highlydeveloped technological infrastructures, but also greater access to on-site expertise, and thus were better able to anticipate and provide for teacher needs. Enhanced teacher use of the laptops would seem to require access to facilities, professional development, technical support and organizational and administrative systems to help teachers take maximum advantage of exclusive use of a laptop. Leadership support for these would seem to be essential (Becker, 1994).

\section{References}

Anderson, R., \& Dexter, S. (2000). School technology leadership: Incidence and impact. Irvine: University of California, Centre for Research on Information Technology and Organizations.

Bebell, D., Russell, M., \& O’Dwyer, L. (2004). Measuring teachers' technology uses: Why multiple-measurers are more revealing. Boston, MA: Boston College, Technology and Assessment Study Collaborative.

Becker, H. (1994). How exemplary computer-using teachers differ from other teachers: Implications for realizing the potential of computers in schools. Journal of Research on Computing in Education, 26(3), 291-321. 
Becker, H., \& Ravitz, J. (1999). The influence of computer and internet use on teachers' pedagogical practices and perceptions. Journal of Research on Computing in Education, 31(4), 356-384.

Cowie, B., Jones, A., \& Harlow, A. (2004). Teachers with laptops in New Zealand: Impacts on teachers and their practice. Paper presented at annual conference of New Zealand Association for Research in Education, Wellington.

Cowie, B., Jones, A., \& Harlow, A. (2005). The Digital Horizons: Laptops for teachers policy initiative: Impacts and consequences. Paper presented at annual conference of New Zealand Association for Research in Education, Dunedin.

Cuban, L. (2001). Oversold $\mathcal{E}$ underused: Computers in the classroom. Cambridge, MA: Harvard University Press.

Cunningham, M., Kerr, K., McEune, R., Smith, P., \& Harris, S. (2004). Laptops for teachers: An evaluation of the first year of the initiative (ICT in Schools Research and Evaluation Series No. 19). Available online at $<$ www.nfer.ac.uk/research-areas/pims-data/summaries/>

Dale, R., Robertson, S., \& Shortis, T. (2004). "You can't not go with the technological flow, can you?" Constructing "ICT" and "teaching and learning". Journal of Computer Assisted Learning, 20, 456-470.

Engelbart, D. (1992). Toward high-performance organizations: A strategic role for groupware. The Bootstrap Institute. <www.bootstrap.org >

Garet, M., Porter, A., Desimone, L., Birman, B., \& Yoon, K. (2001). What makes professional development effective? Analysis of a national sample of teachers. American Educational Research Journal, 38(3), 915-945.

Grossman, P., Stodolsky, S., \& Knapp, M. (2004). Making subject matter part of the equation: The interactions of policy and content. An occasional paper. Seattle, WA: University of Washington, Centre for the Study of Teaching and Policy.

Hayes, D. (2003). Leading technologies: A mid-term analysis of a longitudinal study into the integration of learning technologies in NSW public schools. Paper presented at NZARE/AARE Conference, Auckland.

Harrison, C., Comber, C., Fisher, T., Haw, K., \& Lewin, C. et al. (2003). ImpaCT2: The impact of information and communication technologies on pupil learning and attainment. Coventry: British Educational Communications and Technology Agency (BECTA).
Hennessy, S., Ruthven, K., \& Brindley, S. (2004). Teacher perspectives on integrating ICT into subject teaching: Commitment, constraints, caution and change. Journal of Curriculum Studies, 37(2), 155-192.

Knapp, M. (2002). Understanding how policy meets practice: Two takes on local response to a state reform initiative. Seattle, WA: University of Washington, Centre for the Study of Teaching and Policy.

Knapp, M. (2003). Professional development as a policy tool. Review of Education Research, 27, 109-158.

Lange, D. (1988). Tomorrow's schools: The reform of education administration in New Zealand. Wellington: Government Printer.

Langer, A. (2005). IT and organisational learning. New York: Routledge.

Long, S. (2001). What effect will digital technologies have on visual education in schools? In A. Loveless \& V. Ellis (Eds.), ICT, pedagogy and the curriculum (pp. 199-215). London: Routledge/Falmer.

Loveless, A., Devoogd, G., \& Bohlin, R. (2001). Something old, something new .... : Is pedagogy affected by ICT? In A. Loveless \& V. Ellis (Eds.), ICT, pedagogy and the curriculum (pp. 63-83). London: Routledge/Falmer.

McGee, C., Jones, A., Bishop, R., Cowie, B., Hill, M., Miller, T., Harlow, A., Oliver, D., Taikiwai, S., \& MacKenzie, K. (2002). Teachers' experiences in implementing the New Zealand national curriculum. Hamilton: University of Waikato, Waikato Institute for Research in Learning \& Curriculum, Centre for Science \& Technology Education, Research and Māori Education Research Institute.

Means, B., Roschelle, J., Penuel, W., Sabelli, N., \& Haertel, J. (2003). Technology's contribution to teaching and policy: Efficiency, standardisation, or transformation? Review of Education Research, 27, 159-182.

Ministry of Education. (2002). Digital horizons: Learning through ICT. Wellington: Learning Media.

Ministry of Education. (2003). The Digital Horizons: Laptops for Teachers Scheme. Wellington: Learning Media.

Olson, J. (2000). Trojan horse or teacher's pet? Computers and the culture of the school. Journal of Curriculum Studies, 32(1), 1-8.

Organisation for Economic Co-operation and Development. (2001). Schools for tomorrow. Learning to change: ICT in schools. Paris: OECD. 
Salomon, G. (1993). On the nature of pedagogic computer tools: The case of the writing partner. In S. Lajoie \& S. Derry (Eds.), Computers as Cognitive Tools (pp. 179-196). New Jersey: Lawrence Elhbaum.

Selwyn, N. (1999). Why the computer is not dominating schools: A failure of policy or a failure of practice? Cambridge Journal of Education, 29(1), 77-91.

Senge, P. (1994). The fifth discipline: The art and practice of the learning organization. Milsons Point, NSW: Random House.

Spillane, J. (2004). Standards deviation: How schools misunderstand education policy. Cambridge, MA: Harvard University Press.

Windschitl, M., \& Sahl, K. (2002). Tracing teachers' use of technology in a laptop computer school: The interplay of teacher beliefs, social dynamics, and institutional culture. American Educational Research Journal, 39(1), 165-205.

\section{The authors}

Bronwen Cowie is Director of the Centre for Science and Technology Education Research, University of Waikato. She is a co-director of the Digital Horizons: Laptops for teachers evaluation study. Her research interests include assessment for learning, science education, classroom interactions, mixed methods educational research and curriculum development.

Alister Jones is Director of the Wilf Malcolm Institute of Educational Research, University of Waikato. He is a co-director of the Digital Horizons: Laptops for teachers evaluation study. His research interests include technology education, biotechnology education, assessment for learning, classroom interactions and curriculum development.

Ann Harlow is a Research Officer with the Wilf Malcolm Institute of Educational Research, The University of Waikato, with responsibility for the analysis of data for the laptops evaluation study. She has a background in teaching and has been involved in research on School Support Services, science and technology education, transition, and the curriculum stocktake project.

\section{Acknowledgement}

The authors wish to acknowledge support from the Ministry of

Education for funding the study reported in this article. 